\title{
Analysis of Incidence and Clinical Characteristics of RSV Infection in Hospitalized Children: A Retrospective Study
}

This article was published in the following Dove Press journal: Risk Management and Healthcare Policy

\author{
Ling Gong ${ }^{1,2, *}$ \\ Chunyan $\mathrm{Wu}^{2, *}$ \\ Mingjie $\mathrm{Lu}^{2}$ \\ Chengyan Huang ${ }^{2}$ \\ Yongqian Chen ${ }^{2}$ \\ Zhu Li ${ }^{2}$ \\ Guichuan Huang ${ }^{2}$ \\ Daishun Liu ${ }^{2}$ \\ Xiaoping Tang $\mathbb{D}^{1,3}$
}

'The First Clinical Medical College, Jinan University, Guangzhou, 510632, People's Republic of China; ${ }^{2}$ Department of Respiratory Medicine, The First People's Hospital of Zunyi (The Third Affiliated Hospital of Zunyi Medical University), Zunyi, 563000, People's Republic of China; ${ }^{3}$ Infectious Disease Department, Guangzhou Eighth People's Hospital (the Affiliated Hospital ofGuangzhou Medical University), Guangzhou, 510060, People's Republic of China

*These authors contributed equally to this work

Correspondence: Daishun Liu Department of Respiratory Medicine, The First People's Hospital of Zunyi (The

Third Affiliated Hospital of Zunyi Medical University), No. 98 Fenghuang Road,

Zunyi, Guizhou, 563000, People's

Republic of China

Email IdsIwtg@I26.com

Xiaoping Tang

The First Clinical Medical College, Jinan University, 60I W. Huangpu Avenue,

Guangzhou 510632, Guangdong, China; Guangzhou Eighth People's Hospital,

Guangzhou Medical University, No. 627

Dongfeng East Road, YueXiu District,

Guangzhou, Guangdong, 510060, People's

Republic of China

Email txpdoc@I26.com
Objective: To investigate the incidence and clinical characteristics of hospitalized children with respiratory syncytial virus (RSV) infection, and to provide evidence for the importance of preventive strategies and improvements in supportive care of RSV infection.

Methods: This retrospective study included children under 14 years who received throat swab test and were diagnosed with RSV infection from January 2019 to December 2020. Throat swabs and intravenous blood were the main sources of samples, which were obtained within 24 hours of hospitalization. Direct immunofluorescence assay was used to diagnose RSV infection.

Results: Among the 448 hospitalized children with RSV infection, males (71.9\%) showed the highest proportion, the highest incidence was found in children $<6$ months old $(45.3 \%)$, and $76.6 \%$ of them had pneumonia. Pharyngeal redness, cough, expectoration, and mental fatigue were the most common symptoms in hospitalized children of all ages. More than $60 \%$ of hospitalized children had increased lymphocyte count, aspartate aminotransferase, creatine kinase-MB form, lactate dehydrogenase, and $\alpha$-HBDH levels. The rates of myocardial damage, respiratory failure, stay in the intensive care unit (ICU), use of mechanical ventilation, and absorption of oxygen were higher in children $<6$ months old. Except for children who were 37-60 months old, the percentage of length of hospital stay $\geq 7$ days in the other age groups was greater than $62.0 \%$. Except for children who were 0-28 days old and $>61$ months old, the other age groups showed a re-hospitalization situation due to reinfection with RSV. In hospitalized children diagnosed with RSV infection from throat swabs, we also performed the RSV IgM test and found that $59.2 \%$ of them were positive, $8.0 \%$ of them were weakly positive, and $32.8 \%$ of them were negative.

Conclusion: This study analyzes the incidence and clinical characteristics of hospitalized children with RSV infection, which provides evidence for the importance of preventive strategies and improvements in supportive care of RSV infection.

Keywords: hospitalized children, respiratory syncytial virus infection, incidence, clinical characteristics

\section{Introduction}

Respiratory syncytial virus (RSV) is a negative-sense and single-stranded RNA virus with a filamentous envelope. ${ }^{1} \mathrm{RSV}$ is the main cause of lower respiratory tract infections, such as bronchiolitis and pneumonia, ${ }^{2}$ in infants and young children worldwide, causing over 3.4 million severe infections annually. ${ }^{3,4}$ In children younger than 6 months, about $45 \%$ of hospital admissions and in-hospital deaths were due to RSV infection. ${ }^{3}$ In low- and middle-income countries, more than $80 \%$ of RSV-related acute 
lower respiratory tract infections and more than half of RSVrelated deaths occur in infants older than 6 months. $^{5}$ In children younger than 5 years, about $54 \%$ of deaths are also attributable to RSV infection. ${ }^{6}$ Therefore, RSV is the second leading aetiology of lower respiratory tract infection deaths in children. ${ }^{6}$ The cause of death due to RSV infection is usually apnoea or sepsis. ${ }^{3}$ At present, there is no generally effective treatment and vaccine to prevent the infection. ${ }^{7,8}$ RSV infection leads to hospital admission of children, which causes serious global clinical burden and financial burden. ${ }^{9}$

Therefore, we need to analyze and summarize the incidence and clinical characteristics of hospitalized children with RSV infection to provide evidence for the early preventive strategies and symptomatic treatment. To address the above questions, we retrospectively collected RSV-infected children who were hospitalized in the Third Affiliated Hospital of Zunyi Medical University from January 2019 to December 2020, and we analyzed the incidence and clinical characteristics of RSV infection.

\section{Methods}

\section{Study Population and Data Collection}

This retrospective study included children under 14 years of age who received throat swab test and were diagnosed with RSV infection in the Third Affiliated Hospital of Zunyi Medical University from January 2019 to December 2020. Exclusion criteria are shown in Figure 1. Before the start of the study, the parents or legal guardians of all hospitalized children (0-14 years old) included in the study provided written informed consent, and this study was approved by the Ethics Committee of the Third Affiliated Hospital of Zunyi Medical University and was conducted in accordance with the Declaration of Helsinki-1964.
The medical records of children were retrospectively reviewed, and the following data were recorded: gender, age, body temperature, pulse, respiratory rate, clinical manifestations (including pharyngeal redness, cough, expectoration, rhinobyon, runny nose, shortness of breath, mental fatigue, lack of appetite, vomiting, drowsiness, and dyspnea), laboratory data (including white blood cell count, neutrophil percentage, lymphocyte count, platelet count, C-reactive protein, serum creatinine, aspartate aminotransferase, alanine aminotransferase, creatine kinase-MB form, creatine kinase, lactate dehydrogenase, and $\alpha-\mathrm{HBDH})$, chest CT examination, serum RSV IgM test, intensive care unit (ICU) stay, mechanical ventilation, oxygen absorption, length of hospital stay, complications, $\geq 2$ episodes of hospitalization due to RSV infection.

\section{Specimen Collection and Detection}

Throat swabs and intravenous blood were the main sources of samples, which were obtained within 24 hours of hospitalization. Throat swabs were collected from all hospitalized children by trained nurses using a COPAN flocked swab (FLOQSwabs; Copan Flock Technologies S. r. 1., Brescia, Italy), according to the standard protocols.

The child's name and bed number were checked, and the sampling process and purpose were explained to the child's parents. The parents were asked to help in fixing the child's upper limbs and head. After disinfecting the hands, a COPAN flocked swab was quickly inserted and slightly rotated over the posterior pharyngeal wall for about 5 times, and then it was removed. The tip of the swab was broken off and put into a sampling tube containing $3 \mathrm{~mL}$ of virus preservation solution. The cap of the virus collection tube was tightened, the information of the child was checked again, the label was affixed, and the tube was transferred to the laboratory for

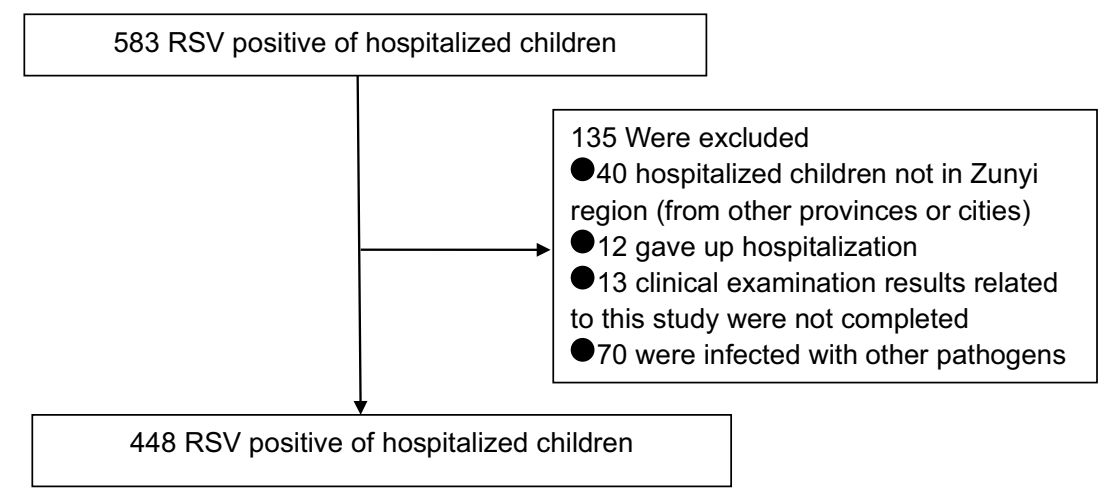

Figure I Exclusion criteria of hospitalized children with RSV infection. 
nucleic acid testing as soon as possible. RSV was detected in children's samples using a commercially available $\mathrm{D}^{3}$ Ultra DFA Respiratory Virus Screen and ID Kit (Diagnostic Hybrids, Inc, Athens, Ohio), according to the manufacturer's instructions.

\section{Statistical Analysis}

Data were processed and analyzed using Microsoft Excel 2010 and SPSS statistical software package (version 19.0; SPSS, Inc., Chicago, IL, USA). All categorical variables were reported as frequency and percentage. Quantitative data were reported as median with interquartile range.

\section{Results}

A total of 583 hospitalized children aged 0 day to 14 years who were diagnosed with RSV infection were initially enrolled. Based on to the inclusion and exclusion criteria, 448 hospitalized children were finally enrolled, and $71.9 \%$ of hospitalized children $(\mathrm{N}=448)$ were male. According to the statistics of different age groups, we found that the three age groups with a higher incidence of RSV infection were 29 days -6 months old (43.1\%), 7-12 months old (25.6\%), and 13-36 months old (20.8\%) age groups (Table 1). Moreover, most of the hospitalized children with RSV infection were 29 days-6 months old (Table 1).

As shown in Table 2, we counted the rate of abnormal pulse and respiratory rate of hospitalized children with RSV infection in different age groups. Children of different ages have different ranges of normal pulse and respiratory rate. Considering the normal range of pulse as the reference, we found that $50 \%$ of children $(\mathrm{N}=10)$ with

Table I Demographic Characteristics of Hospitalized Children with RSV Infection

\begin{tabular}{|l|c|}
\hline Characteristics & $\begin{array}{c}\text { Total } \\
\mathbf{( N = 4 4 8 )} \\
\mathbf{n}(\%)\end{array}$ \\
\hline Sex & \\
Male & $322(71.9)$ \\
Female & $126(28.1)$ \\
\hline Age (days and months) & \\
0 d-28 d & $10(2.2)$ \\
$29 \mathrm{~d}-6$ mo & $193(43.1)$ \\
7 mo- 12 mo & $115(25.6)$ \\
I3 mo-36 mo & $93(20.8)$ \\
37 mo-60 mo & $21(4.7)$ \\
$>61$ mo & $16(3.6)$ \\
\hline
\end{tabular}

abnormal pulse were 0 day-28 days old, $75.1 \%$ of children $(\mathrm{N}=378)$ with abnormal pulse were 29 days-23 months old, $65.8 \%$ of children $(\mathrm{N}=38)$ with abnormal pulse were 24-47 months old, $85.7 \%$ of children with abnormal pulse $(\mathrm{N}=14)$ were $48-84$ months old, and $100.0 \%$ of children $(\mathrm{N}=8)$ with abnormal pulse were $>85$ months old. Therefore, hospitalized children with RSV infection generally had an abnormal pulse. Considering the normal range of respiratory rate and the number of people $>50 \%$ as the reference, we found that the three age groups with a higher abnormal respiratory rate were 0-28 days old (100.0\%), 48-84 months old (64.3\%), and $>85$ months old $(75.0 \%)$ age groups.

As shown in Table 3, we counted the rate of clinical symptoms of hospitalized children with RSV infection in the different age groups. Considering the number of people $>50 \%$ as the reference, pharyngeal redness, cough, expectoration, and mental fatigue were the most common symptoms, but the rate of expectoration in children 37-60 months old was slightly less than $50 \%$. Rhinobyon, runny nose, vomiting, drowsiness, and dyspnea were the least common symptoms. Compared with the other age groups, shortness of breath was the most common symptom in children who were 29 days -6 months old (52.3\%), and lack of appetite was the most common symptom in children who were 0-28 days old (60.0\%) and 29 days-6 months old (64.3\%).

As shown in Table 4, we counted the rate of fever and analyzed the laboratory test results of hospitalized children with RSV infection. We found that $79.7 \%$ of hospitalized children $(\mathrm{N}=448)$ had no fever. Further, $8.9 \%$ of hospitalized children had fever in the range of $37.3^{\circ} \mathrm{C}-38^{\circ}$ $\mathrm{C}, 7.8 \%$ had fever in the range of $38.1^{\circ} \mathrm{C}-39^{\circ} \mathrm{C}, 3.4 \%$ had fever in the range of $39.1^{\circ} \mathrm{C}-41^{\circ} \mathrm{C}$, and $0.2 \%$ had fever $>41^{\circ} \mathrm{C}$. There was no important clinical significance in some baseline laboratory test results, such as white blood cell count, neutrophil percentage, platelet count, serum creatinine, alanine aminotransferase, and creatine kinase. The proportion of lymphocyte count $>4.0 \times 10^{9} /$ liter in hospitalized children was $67.2 \%$, and the median lymphocyte count was $5.3 \times 10^{9} /$ liter (IQR, 3.5 to $7.7 \times 10^{9}$ / liter). The proportion of aspartate aminotransferase $>40 \mathrm{U} /$ liter in hospitalized children was $68.8 \%$, and the median aspartate aminotransferase level was $45.8 \mathrm{U} /$ liter (IQR, 37.7 to $58.7 \mathrm{U} /$ liter). The proportion of creatine kinase$\mathrm{MB}$ form $>25 \mathrm{U} /$ liter in hospitalized children was $64.1 \%$, and the median level of creatine kinase-MB form was 28.5 U/liter (IQR, 22.9 to $35.2 \mathrm{U} /$ liter). The proportion 
Table 2 Characteristics of Abnormal Pulse and Respiratory Rate in Hospitalized Children with RSV Infection

\begin{tabular}{|l|c|c|c|c|}
\hline Age & $\begin{array}{c}\text { Normal Range of Pulse } \\
\text { (per Minute) }\end{array}$ & $\mathbf{n ~ ( \% )}$ & $\begin{array}{c}\text { Normal Range of Respiratory } \\
\text { Rate (per Minute) }\end{array}$ & $\mathbf{n}$ (\%) \\
\hline $0 \mathrm{~d}-28 \mathrm{~d}(\mathrm{~N}=10)$ & $120-140$ & $5(50.0)$ & $40-45$ & $10(100.0)$ \\
$29 \mathrm{~d}-23 \mathrm{mo}(\mathrm{N}=378)$ & $110-130$ & $284(75.1)$ & $30-40$ & $165(43.7)$ \\
$24 \mathrm{mo}-47 \mathrm{mo}(\mathrm{N}=38)$ & $100-120$ & $25(65.8)$ & $25-30$ & $10(26.3)$ \\
$48 \mathrm{mo}-84 \mathrm{mo}(\mathrm{N}=14)$ & $80-100$ & $12(85.7)$ & $20-25$ & $9(64.3)$ \\
$>85 \mathrm{mo}(\mathrm{N}=8)$ & $70-90$ & $8(100.0)$ & $18-20$ & $6(75.0)$ \\
\hline
\end{tabular}

Table 3 Clinical Symptoms of Hospitalized Children with RSV Infection

\begin{tabular}{|c|c|c|c|c|c|c|}
\hline Symptoms & $\begin{array}{c}0 \mathrm{~d}-28 \mathrm{~d} \\
(\mathrm{~N}=10) \\
n(\%)\end{array}$ & $\begin{array}{c}29 \text { d-6 mo } \\
(\mathrm{N}=193) \\
n(\%)\end{array}$ & $\begin{array}{c}7 \mathrm{mo}-12 \mathrm{mo} \\
(\mathrm{N}=1 \mathrm{I5}) \\
\mathrm{n}(\%)\end{array}$ & $\begin{array}{c}13 \mathrm{mo}-36 \mathrm{mo} \\
(\mathrm{N}=93) \\
\mathrm{n}(\%)\end{array}$ & $\begin{array}{c}37 \mathrm{mo}-60 \mathrm{mo} \\
(\mathrm{N}=2 \mathrm{I}) \\
\mathrm{n}(\%)\end{array}$ & $\begin{array}{c}>61 \mathrm{mo} \\
(\mathrm{N}=16) \\
\mathrm{n}(\%)\end{array}$ \\
\hline Pharyngeal redness & $10(100.0)$ & $193(100.0)$ & III (96.5) & $88(94.6)$ & $21(100.0)$ & $15(93.8)$ \\
\hline Cough & $9(90.0)$ & 191 (99.0) & $109(94.8)$ & $79(85.0)$ & I5 (7I.4) & $13(81.3)$ \\
\hline Expectoration & $9(90.0)$ & $186(96.4)$ & $100(87.0)$ & $63(67.7)$ & $10(47.6)$ & II (68.8) \\
\hline Rhinobyon & I (I0.0) & $32(16.6)$ & $9(7.8)$ & $15(16.1)$ & $0(0.0)$ & I (6.3) \\
\hline Runny nose & $I(10.0)$ & $42(21.8)$ & $23(20.0)$ & $32(34.4)$ & $7(33.3)$ & $4(25.0)$ \\
\hline Shortness of breath & $4(40.0)$ & $101(52.3)$ & 39 (33.9) & $30(32.3)$ & I (4.8) & $0(0.0)$ \\
\hline Mental fatigue & $9(90.0)$ & 149 (77.2) & $85(73.9)$ & $56(60.2)$ & 15 (7I.4) & $9(56.3)$ \\
\hline Lack of appetite & $6(60.0)$ & $124(64.3)$ & $57(49.6)$ & $45(48.4)$ & $8(38.1)$ & $6(37.5)$ \\
\hline Vomiting & $2(20.0)$ & $45(23.3)$ & $13(1 \mid .3)$ & $14(15.1)$ & $3(14.3)$ & $3(18.8)$ \\
\hline Drowsiness & $2(20.0)$ & I7 (8.8) & $4(3.5)$ & $2(2.2)$ & $0(0.0)$ & $0(0.0)$ \\
\hline Dyspnea & $3(30.0)$ & $28(14.5)$ & $8(7.0)$ & $2(2.2)$ & $0(0.0)$ & $0(0.0)$ \\
\hline
\end{tabular}

of lactate dehydrogenase $>245 \mathrm{U} /$ liter in hospitalized children was $97.5 \%$, and the median level of lactate dehydrogenase was $332.6 \mathrm{U} /$ liter (IQR, 291.8 to $382.1 \mathrm{U} /$ liter). The proportion of $\alpha-\mathrm{HBDH}>180 \mathrm{U} /$ liter in hospitalized children was $79.0 \%$, and the median $\alpha$-HBDH level was 213.7 U/liter (IQR, 183.5 to 241.7 U/liter). Chest CT examination of hospitalized children with RSV infection revealed pneumonia in $76.6 \%$ of children. In hospitalized children diagnosed with RSV infection from throat swabs, we also performed the RSV IgM test and found that $59.2 \%$ of them were positive, $8.0 \%$ of them were weakly positive and $32.8 \%$ of them were negative.

As shown in Table 5, we counted the rate of status and treatments of hospitalized children with RSV infection in the different age groups. The 0-28 days old and 29 days- 6 months old children had higher rates of stay in the ICU, use of mechanical ventilation, and absorption of oxygen than hospitalized children in the other age groups. Except for the 37-60 months old age group, the percentage of length of hospital stay $\geq 7$ days in the other age groups was greater than $60.0 \%$. Complications found in all age groups were myocardial damage, respiratory failure, and sepsis. The rates of myocardial damage and respiratory failure in the 0-28 days old and 29 days -6 months old age groups were higher than those in the other age groups. Secondary granulocytopenia, liver function damage, and kidney function damage were uncommon complications. Except for the 0-28 days old and $>61$ months old age groups, the other age groups had a re-hospitalization situation due to re-infection with RSV.

\section{Discussion}

The present study promotes our understanding of incidence and clinical characteristics of hospitalized Chinese children under 14 years of age with RSV infection, and it provides epidemiological data from a population in Zunyi, a developing city in Southwest China.

Our study found that RSV infection was common in hospitalized children of different ages; the infection most commonly occurred in children $<6$ months old (45.3\%), and the proportion of male children $(71.9 \%)$ was higher than that of female children $(28.1 \%)$, which coincides with 
Table 4 Characteristics of Body Temperature and Laboratory Test Results in Hospitalized Children with RSV Infection

\begin{tabular}{|c|c|}
\hline Characteristics & $\begin{array}{c}\text { Total } \\
(\mathrm{N}=448) \\
\mathrm{n}(\%)\end{array}$ \\
\hline \multicolumn{2}{|l|}{ Body temperature } \\
\hline$<37.2^{\circ} \mathrm{C}$ & 357 (79.7) \\
\hline $37.3^{\circ} \mathrm{C}-38^{\circ} \mathrm{C}$ & $40(8.9)$ \\
\hline $38.1{ }^{\circ} \mathrm{C}-39^{\circ} \mathrm{C}$ & $35(7.8)$ \\
\hline $39.1{ }^{\circ} \mathrm{C}-41{ }^{\circ} \mathrm{C}$ & $15(3.4)$ \\
\hline$>41^{\circ} \mathrm{C}$ & $\mathrm{I}(0.2)$ \\
\hline $\begin{array}{l}\text { White blood cell count }\left(\times 10^{-9} / \text { liter }\right) \text {-median } \\
(\mathrm{IQR})\end{array}$ & $9.8(7.4-12.9)$ \\
\hline $4-10 \times 10^{-9} /$ liter & $219(48.9)$ \\
\hline$<4 \times 10^{-9} /$ liter & $14(3.1)$ \\
\hline$>10 \times 10^{-9} /$ liter & $215(48.0)$ \\
\hline Neutrophil proportion (\%)-median (IQR) & $31(18.8-44.4)$ \\
\hline $50-70 \%$ & $66(14.7)$ \\
\hline$\geq 70 \%$ & $25(5.6)$ \\
\hline$<50 \%$ & $357(79.7)$ \\
\hline Lymphocyte count $\left(\times 10^{-9} /\right.$ liter $)$-median (IQR) & $5.3(3.5-7.7)$ \\
\hline $0.8-4 \times 10^{-9} /$ liter & $144(32.1)$ \\
\hline$<0.8 \times 10^{9} /$ liter & $3(0.7)$ \\
\hline$>4.0 \times 10^{9} /$ liter & $301(67.2)$ \\
\hline Platelet count $\left(\times 10^{-9} /\right.$ liter $)$-median (IQR) & $386.5(29|-47| .8)$ \\
\hline$\geq 100 \times 10^{-9} /$ liter & $442(98.7)$ \\
\hline$<100 \times 10^{-9} /$ liter & $6(1.3)$ \\
\hline \multicolumn{2}{|l|}{ C-reactive protein (mg/liter) } \\
\hline$<10 \mathrm{mg} /$ liter & $383(85.5)$ \\
\hline$\geq 10 \mathrm{mg} / \mathrm{liter}$ & $65(14.5)$ \\
\hline Serum creatinine ( $\mu \mathrm{mol} /$ liter)-median (IQR) & $20.9(17.0-25.3)$ \\
\hline$\leq 97 \mu \mathrm{mol} / \mathrm{liter}$ & 447 (99.8) \\
\hline$>97 \mu \mathrm{mol} / /$ liter & I $(0.2)$ \\
\hline $\begin{array}{l}\text { Aspartate aminotransferase (U/liter)-median } \\
(\mathrm{IQR})\end{array}$ & $45.8(37.7-58.7)$ \\
\hline$\leq 40 \mathrm{U} /$ liter & $140(3 \mid .2)$ \\
\hline >40 U/liter & $308(68.8)$ \\
\hline $\begin{array}{l}\text { Alanine aminotransferase (U/liter)-median } \\
(\mathrm{IQR})\end{array}$ & $22.4(15.8-34.7)$ \\
\hline$\leq 40 \mathrm{U} /$ liter & $359(80.1)$ \\
\hline >40 U/liter & $89(19.9)$ \\
\hline $\begin{array}{l}\text { Creatine kinase-MB Form (U/liter)-median } \\
\text { (IQR) }\end{array}$ & $28.5(22.9-35.2)$ \\
\hline$\leq 25 \mathrm{U} /$ liter & $161(35.9)$ \\
\hline$>25$ U/liter & $287(64.1)$ \\
\hline
\end{tabular}

(Continued)
Table 4 (Continued).

\begin{tabular}{|c|c|}
\hline Characteristics & $\begin{array}{c}\text { Total } \\
(\mathrm{N}=448) \\
\mathrm{n}(\%)\end{array}$ \\
\hline $\begin{array}{l}\text { Creatine kinase (U/liter)-median (IQR) } \\
\quad \leq 140 \mathrm{U} / \mathrm{L} \\
>140 \mathrm{U} / \mathrm{L}\end{array}$ & $\begin{array}{c}99.5(69.5-146.0) \\
328(73.2) \\
120(26.8)\end{array}$ \\
\hline $\begin{array}{l}\text { Lactate dehydrogenase (U/liter)-median (IQR) } \\
\quad \leq 245 \mathrm{U} / \text { liter } \\
>245 \mathrm{U} / \text { liter }\end{array}$ & $\begin{array}{c}332.6 \\
(291.8-382.1) \\
\text { II }(2.5) \\
437(97.5)\end{array}$ \\
\hline $\begin{array}{l}\alpha \text {-HBDH (U/liter)-median (IQR) } \\
\quad \leq 180 \mathrm{U} / \text { liter } \\
\quad>180 \mathrm{U} / \text { liter }\end{array}$ & $\begin{array}{c}213.7 \\
(183.5-24 \mid .7) \\
94(2 \mid .0) \\
354(79.0)\end{array}$ \\
\hline $\begin{array}{l}\text { Chest CT examination } \\
\text { Pneumonia }\end{array}$ & $343(76.6)$ \\
\hline $\begin{array}{l}\text { Serum RSV IgM test } \\
\text { Weakly positive } \\
\text { Positive } \\
\text { Negative }\end{array}$ & $\begin{array}{c}36(8.0) \\
265(59.2) \\
147(32.8)\end{array}$ \\
\hline
\end{tabular}

the results presented by Kombe et $\mathrm{al}^{10} \mathrm{Li}$ et $\mathrm{al}^{11}$ and $\mathrm{Zhu}$ et al. ${ }^{12}$ RSV is the most common pathogen causing pneumonia. ${ }^{13}$ Our study found that $76.6 \%$ of children with RSV infection had pneumonia. The study by Yu et al ${ }^{14}$ showed that the average positivity rate of RSV was $54 \%$ in children with pneumonia aged from 28 days to 5 months.

RSV can cause respiratory tract infection in infants, and eventually pneumonia. The main symptoms include fever, cough, rhinobyon, and wheezing. ${ }^{15}$ In severe cases, it can lead to apnea or even death, and it can also cause a series of complications, such as bronchitis, laryngitis, otitis media, and myocarditis. ${ }^{16}$ However, our findings differed from those of previous studies, and we found that pharyngeal redness, cough, expectoration, and mental fatigue were the most common symptoms in every age group. Moreover, myocardial damage, respiratory failure, and sepsis occurred in children of different ages. The rates of myocardial damage and respiratory failure in the 0-28 days old and 29 days -6 months old age groups were higher than those in the other age groups.

Our study found that children in the 0-28 days old and 29 days-6 months old age groups had a higher rate of stay in the ICU, use of mechanical ventilation, and absorption 
Table 5 Status and Treatments of Hospitalized Children with RSV Infection

\begin{tabular}{|c|c|c|c|c|c|c|}
\hline Characteristics & $\begin{array}{c}0 \mathrm{~d}-28 \mathrm{~d} \\
(\mathrm{~N}=10) \\
n(\%)\end{array}$ & $\begin{array}{c}29 \text { d-6 mo } \\
(\mathrm{N}=193) \\
n(\%)\end{array}$ & $\begin{array}{c}7 \mathrm{mo}-12 \mathrm{mo} \\
(\mathrm{N}=\mathrm{I} \text { I5) } \\
\mathrm{n}(\%)\end{array}$ & $\begin{array}{c}13 \mathrm{mo}-36 \mathrm{mo} \\
(\mathrm{N}=93) \\
\mathrm{n}(\%)\end{array}$ & $\begin{array}{c}37 \mathrm{mo}-60 \mathrm{mo} \\
(\mathrm{N}=2 \mathrm{l}) \\
\mathrm{n}(\%)\end{array}$ & $\begin{array}{c}>61 \mathrm{mo} \\
(\mathrm{N}=16) \\
\mathrm{n}(\%)\end{array}$ \\
\hline ICU stay & $3(30.0)$ & $21(10.9)$ & $9(7.8)$ & $4(4.3)$ & I (4.8) & I (6.3) \\
\hline Mechanical ventilation & $3(30.0)$ & $29(15.0)$ & $13(11.3)$ & $6(6.5)$ & $0(0.0)$ & $2(12.5)$ \\
\hline Oxygen absorption & $7(70.0)$ & $94(48.7)$ & $40(34.8)$ & $21(22.6)$ & $5(23.8)$ & $6(37.5)$ \\
\hline \multicolumn{7}{|l|}{ Length of hospital stay } \\
\hline$<7$ day & $3(30.0)$ & 48 (24.9) & $29(25.2)$ & 35 (37.6) & $12(57.1)$ & $3(18.8)$ \\
\hline$\geq 7$ day & $7(70.0)$ & $145(75.1)$ & $86(74.8)$ & $58(62.4)$ & $9(42.9)$ & $13(8 \mid .2)$ \\
\hline \multicolumn{7}{|l|}{ Complication } \\
\hline Secondary granulocytopenia & $0(0.0)$ & $2(1.0)$ & $0(0.0)$ & $0(0.0)$ & $0(0.0)$ & $0(0.0)$ \\
\hline Liver function damage & $0(0.0)$ & $10(5.2)$ & $2(1.7)$ & $2(2.2)$ & $0(0.0)$ & $0(0.0)$ \\
\hline Kidney function damage & $0(0.0)$ & $\mathrm{I}(0.5)$ & $0(0.0)$ & $0(0.0)$ & $0(0.0)$ & $0(0.0)$ \\
\hline Myocardial damage & $I(10.0)$ & $19(9.8)$ & $12(10.4)$ & $8(8.6)$ & $5(23.8)$ & $2(12.5)$ \\
\hline Respiratory failure & $3(30.0)$ & $30(15.5)$ & $10(8.7)$ & $9(9.7)$ & I (4.8) & $2(12.5)$ \\
\hline Sepsis & I $(10.0)$ & $3(1.6)$ & $3(2.6)$ & $8(8.6)$ & $2(9.5)$ & $I(6.3)$ \\
\hline $\begin{array}{l}\text { Re-hospitalization situation due to re- } \\
\text { infection with RSV }\end{array}$ & $0(0.0)$ & $9(4.7)$ & $5(4.4)$ & $3(3.2)$ & I (4.8) & $0(0.0)$ \\
\hline
\end{tabular}

of oxygen than hospitalized children in the other age groups. Arriola et al ${ }^{17}$ conducted a study in 1554 children under the age of 2 years who were hospitalized in the community with RSV infection. They found that $27 \%$ of children were admitted to an ICU, and $6 \%$ of these children needed mechanical ventilation.

Our study found that, with the exception of the 37-60 months old age group, the proportion of length of hospital stay $\geq 7$ days in the other age groups was greater than $62.0 \%$. However, Papan et $\mathrm{al}^{18}$ found that the average hospital stay was about 5 days in a study of hospitalized children under 2 years of age with RSV infections.

Our study found that except for the 0-28 days old and $>61$ months old age groups, the other age groups had a re-hospitalization situation due to re-infection with RSV. Wong et $\mathrm{al}^{19}$ conducted a retrospective analysis of hospitalized children with RSV infection in Alberta, Canada over 13 years. They found that a total of 666 children (6.5\%) were re-infected with RSV, of whom 433 (4.2\%) were re-infected within 30 days of the initial hospital discharge; and in the same RSV season, 36 children (0.35\%) had two RSV admissions $>30$ days.

There are some limitations to the present study. First, the clinical analysis of hospitalized children with RSV infection in our hospital from January 2019 to December 2020 may not fully reflect the situation and epidemiological characteristics.
Therefore, it is necessary to expand the scope of investigation to accurately reveal the clinical symptoms, treatment, and epidemiological characteristics of hospitalized children with RSV infection. Second, this was a single-center study, and a multicenter study is needed to verify the results. Third, all data were obtained from retrospective analysis.

\section{Conclusion}

In summary, our study analyzes the incidence and clinical characteristics of children with RSV infection, which provides evidence for the importance of preventive strategies and improvements in supportive care of RSV infection.

\section{Acknowledgment}

This study was supported by grants from Natural Science Foundation of China (No.82060010), Guizhou Provincial Natural Science Foundation Project ([2018]5623), Guizhou Provincial Respiratory Critical Disease Clinical Research and Prevention and Treatment Talent Base Project ([2020]8), Zunyi Respiratory Medicine Talent Base Project ([2019]69), Science and Technology Bureau Project of Zunyi City (Zunshi Kehe [2015]17, Zunshi Kehe HZ[2020]3 and [2020]292).

\section{Disclosure}

The authors report no conflicts of interest for this work. 


\section{References}

1. Battles MB, McLellan JS. Respiratory syncytial virus entry and how to block it. Nat Rev Microbiol. 2019;17:233-245.

2. Mejias A, Garcia-Maurino C, Rodriguez-Fernandez R, Peeples ME, Ramilo O. Development and clinical applications of novel antibodies for prevention and treatment of respiratory syncytial virus infection. Vaccine. 2017;35:496-502.

3. Shi T, McAllister DA, O’Brien KL, et al. Global, regional, and national disease burden estimates of acute lower respiratory infections due to respiratory syncytial virus in young children in 2015: a systematic review and modelling study. Lancet. 2017;390:946-958.

4. Kirolos A, Christides A, Xian S, Reeves R, Nair H, Campbell H. A landscape review of the published research output relating to respiratory syncytial virus (RSV) in North \& Central America and Europe between 2011-2015. J Glob Health. 2019;9:010425.

5. Karron RA, Black RE. Determining the burden of respiratory syncytial virus disease: the known and the unknown. Lancet. 2017;390:917-918.

6. Estimates of the global, regional, and national morbidity, mortality, and aetiologies of lower respiratory infections in 195 countries, 1990-2016: a systematic analysis for the Global Burden of Disease Study 2016. Lancet Infect Dis. 2018;18:1191-1210.

7. Karron RA, Luongo C, Mateo JS, Wanionek K, Collins PL, Buchholz UJ. Safety and immunogenicity of the respiratory syncytial virus vaccine $\mathrm{RSV} / \Delta \mathrm{NS} 2 / \Delta 1313 / \mathrm{I} 1314 \mathrm{~L}$ in RSV-seronegative children. J Infect Dis. 2020;222:82-91.

8. Pålsson SA, Dondalska A, Bergenstråhle J, et al. Single-stranded oligonucleotide-mediated inhibition of respiratory syncytial virus infection. Front Immunol. 2020;11:580547.

9. Barr R, Green CA, Sande CJ, Drysdale SB. Respiratory syncytial virus: diagnosis, prevention and management. Ther Adv Infect Dis. 2019;6:2049936119865798
10. Kombe IK, Agoti CN, Munywoki PK, Baguelin M, Nokes DJ, Medley GF. Integrating epidemiological and genetic data with different sampling intensities into a dynamic model of respiratory syncytial virus transmission. Sci Rep. 2021;11:1463.

11. Li L, Ni YA, Song Z, Yi Z, Wang F. Identification of pathogenic genes and transcription factors in respiratory syncytial virus. $B M C$ Pediatr. 2021;21:27.

12. Zhu G, Xu D, Zhang Y, et al. Epidemiological characteristics of four common respiratory viral infections in children. Virol J. 2021;18:10.

13. Núñez-Samudio V, Landires I. Epidemiology of viral respiratory infections in a pediatric reference hospital in Central Panama. BMC Infect Dis. 2021;21:43.

14. Yu J, Liu C, Xiao Y, et al. Respiratory syncytial virus seasonality, Beijing, China, 2007-2015. Emerg Infect Dis. 2019;25:1127-1135.

15. Zhang RF, Jin Y, Xie ZP, et al. Human respiratory syncytial virus in children with acute respiratory tract infections in China. $J$ Clin Microbiol. 2010;48:4193-4199.

16. Bashir U, Nisar N, Arshad Y, et al. Respiratory syncytial virus and influenza are the key viral pathogens in children $<2$ years hospitalized with bronchiolitis and pneumonia in Islamabad Pakistan. Arch Virol. 2017;162:763-773.

17. Arriola CS, Kim L, Langley G, et al. Estimated burden of community-onset respiratory syncytial virus-associated hospitalizations among children aged $<2$ years in the United States, 2014-15. J Pediatric Infect Dis Soc. 2020;9:587-595.

18. Papan C, Willersinn M, Weiß C, Karremann M, Schroten H, Tenenbaum T. Antibiotic utilization in hospitalized children under 2 years of age with influenza or respiratory syncytial virus infection a comparative, retrospective analysis. BMC Infect Dis. 2020;20:606.

19. Wong K, Robinson JL, Hawkes MT. Risk of repeated admissions for respiratory syncytial virus in a cohort of $>10000$ hospitalized children. J Pediatric Infect Dis Soc. 2020.
Risk Management and Healthcare Policy

\section{Publish your work in this journal}

Risk Management and Healthcare Policy is an international, peerreviewed, open access journal focusing on all aspects of public health, policy, and preventative measures to promote good health and improve morbidity and mortality in the population. The journa welcomes submitted papers covering original research, basic science, clinical \& epidemiological studies, reviews and evaluations, guidelines, expert opinion and commentary, case reports and extended reports. The manuscript management system is completely online and includes a very quick and fair peer-review system, which is all easy to use. Visit http://www.dovepress.com/testimonials.php to read real quotes from published authors. 